\title{
Graphene as a lubricant on Ag for electrical contact applications
}

\author{
Fang Mao' ${ }^{1} \cdot$ Urban Wiklund $^{2} \cdot$ Anna M. Andersson $^{3} \cdot$ Ulf Jansson $^{1}$
}

Received: 28 April 2015/Accepted: 25 June 2015/Published online: 3 July 2015

(C) The Author(s) 2015. This article is published with open access at Springerlink.com

\begin{abstract}
The potential of graphene as a solid lubricant in sliding Ag-based electrical contacts has been investigated. Graphene was easily and quickly deposited by evaporating a few droplets of a commercial graphene solution in air. The addition of graphene reduced the friction coefficient in an $\mathrm{Ag} / \mathrm{Ag}$ contact with a factor of $\sim 10$. The lubricating effect was maintained for more than 150,000 cycles in a pin-on-disk test at $1 \mathrm{~N}$. A reduction in friction coefficient was also observed with other counter surfaces such as steel and $\mathrm{W}$ but the life time was strongly dependent on the materials combination. $\mathrm{Ag} / \mathrm{Ag}$ contacts exhibited a significantly longer life time than steel/Ag and W/Ag contacts. The trend was explained by an increased affinity for metalcarbon bond formation.
\end{abstract}

\section{Introduction}

Electrical contacts are important in modern technology. From a materials science point of view, the design of such contacts is a complex problem, in particular for a sliding contact. In general, a contact material must have a low resistivity, a low contact resistance, a high corrosion resistance, and also be reasonable inexpensive. For a sliding contact, additional materials properties are required. The material cannot be too soft and must exhibit a low

Fang Mao

fang.mao@kemi.uu.se

1 Department of Chemistry-Ångström Laboratory, Uppsala University, Box 538, 75121 Uppsala, Sweden

2 Department of Engineering Sciences, Uppsala University, Box 534, 75121 Uppsala, Sweden

3 ABB AB, Corporate Research, 72178 Västerås, Sweden wear rate. In addition, a low friction coefficient between the sliding surfaces is required. All these properties are difficult to combine in one single material and the development of new, more reliable contact materials is therefore a true challenge.

One of the most widely used contact materials is Ag. This noble metal exhibits a low resistivity and low contact resistance. The disadvantages of $\mathrm{Ag}$, are the rather high materials costs and the fact that it form surface compounds such as sulfides which may be detrimental for the performance. Most important of all, in a sliding contact application, it is too soft and the friction coefficient between two sliding Ag surfaces is far too high $(>1)$. Consequently, there is a need to modify the $\mathrm{Ag}$ surfaces to reduce the friction coefficient by e.g., adding a surface coating on the $\mathrm{Ag}$ contact. One example for such coating is $\mathrm{AgI}$ which can be deposited by electrochemical techniques or by exposure to an $I_{2}$ solution [1-3]. Ag versus AgI-coated Ag contacts typically exhibit a friction coefficient of 0.3 but have a limited life time as the AgI coatings have a rather high wear rate [3]. Hence, other methods to produce low friction surfaces on Ag contacts with long lifetimes are needed.

One of the emerging lubricating materials is graphene, which has been widely studied for its remarkable mechanical, electrical, optical, and thermal properties [47]. The tribological properties, especially as a lubricating additive, have attracted intense research attention as well [8-13]. Recently, however, Berman et al. demonstrated that the addition of few-layer graphene flakes to a steel surface can significantly reduce the friction coefficient from $\sim 1$ to about 0.15 against steel in a pin-on-disk test $[14,15]$. It is conceivable that graphene layers (GL) also could drastically reduce the friction coefficient for a sliding $\mathrm{Ag} / \mathrm{Ag}$ contacts but this has yet not been demonstrated. $\mathrm{Ag}$ interacts weakly with graphene and forms weak $\mathrm{Ag}-\mathrm{C}$ 
bonds. It is therefore possible that the tribological behavior for a graphene-coated Ag surface can be quite different compared to a graphene-coated steel surface where stronger interactions with graphene and also stronger $\mathrm{Fe}-\mathrm{C}$ bonds are expected. Furthermore, it is possible to design a contact where a Ag surface is sliding against a counter surface of another metal or alloy. In this case, the graphene can be expected to exhibit different effects on the tribological properties depending on the metal-graphene interactions.

The aim of this study is to investigate the potential use of graphene in sliding Ag-based contacts. Also, trends of metal-graphene interactions are studied by using $\mathrm{Ag} / \mathrm{Ag}$, $\mathrm{Ag} / \mathrm{steel}$, and $\mathrm{Ag} / \mathrm{W}$ contacts. Me-C bond strength is known to vary among the transition metals where $\mathrm{W}$ shows the strongest bonds and Ag the weakest. Fe-based alloys such as steel are therefore expected to exhibit intermediate bond strength to carbon. We have investigated the tribological behavior of these materials combinations with added graphene and characterized the contacts with Raman spectroscopy and X-ray photoelectron spectroscopy (XPS).

\section{Materials and methods}

Tribological studies of flat Ag samples with and without added graphene were performed using a ball-on-disk tribometer (from VIT) with rotation geometry at room temperature. The flat Ag samples from Alfa Aesar (99.95\% purity) were polished and its roughness was measured using an optical profiler WYKO NT1100 (from Veeco/ WYKO) to $R_{\mathrm{q}}=\sim 18 \mathrm{~nm}$. The counter materials were a silver-coated cylindrical $\mathrm{Cu}$ rod with a hemispherical tip of $9 \mathrm{~mm}$ diameter with $R_{\mathrm{q}}=\sim 60 \mathrm{~nm}$, bearing steel balls of $6 \mathrm{~mm}$ diameter with $R_{\mathrm{q}}=\sim 10 \mathrm{~nm}$, and tungsten balls of $8 \mathrm{~mm}$ diameter with $R_{\mathrm{q}}=\sim 50 \mathrm{~nm}$. All the specimens were cleaned by sonication in acetone, and then in isopropanol and followed by flushing in dry $\mathrm{N}_{2}$ to clean up any contaminants left from the sample preparation and polishing steps. All of the tribological tests were carried out at a sliding speed of $0.02 \mathrm{~m} / \mathrm{s}$ with contact track of $2.5 \mathrm{~mm}$ radius. The friction coefficient was continually recorded during each test. Two different normal loads were applied for the tribological tests; $2 \mathrm{~N}$ normal load was used for lifetime testing of lubricating GL, while more detailed comparisons between different balls against $\mathrm{Ag}$ with added graphene were performed using a normal load of $1 \mathrm{~N}$. A graphene-containing ethanol solution $(1 \mathrm{mg} / \mathrm{L})$ from Graphene Supermarket Inc. was used a graphene source. The solution contained monolayer graphene with an average flake size of $550 \mathrm{~nm}$. Before the tribological tests, three droplets of the graphene solution were added on the highly polished silver plate surface and allowed to evaporate in ambient atmosphere (humidity $30 \%$ ).

The surface morphology was studied using a scanning electron microscopy (SEM; Merlin, Zeiss) with a field emission gun as the electron source and an acceleration voltage of $5 \mathrm{kV}$. After the tribological tests, the contact tracks were examined using Raman spectroscopy, using a red laser light $(\lambda=633 \mathrm{~nm})$ in a Renishaw Invia-Raman spectroscope. The chemical bonds in the contact tracks were studied with XPS using a Physical Systems Quantum 2000 spectrometer with monochromated $\mathrm{Al} \mathrm{K} \alpha$ radiation. The analysis was performed with an analysis spot of $50 \mu \mathrm{m}$ without any pre-sputtering. The instrument was calibrated against $\mathrm{Au}$, $\mathrm{Ag}$, and $\mathrm{Cu}$ references. The composition ratio of $\mathrm{Ag} / \mathrm{C}$ on the surface of the contact tracks was estimated using XPS areas and sensitivity factors given by the Physical Electronics Software MultiPak V6.1A. The imaging of the contact tracks was performed with an Olympus optical microscope (from Leitz). The roughness and height profile of the sample surface of the contact tracks were determined with an optical profiler WYKO NT1100 (from Veeco/WYKO).

The contact resistances of the Ag surface and the graphene-coated Ag were measured using a custom-made setup, based on a four-point resistance method, measuring the voltage drop as a current flows from the probe tip to the test surface. The terminal on the probe is placed as close to the contact point as possible to ensure the distance for shared path of current and voltage is as short as possible to reduce the resistance contribution from probe. The path of the current and voltage divides immediately after the contact point to ensure the contact resistance measurement is not affected by the sheet resistance of the measured film or the internal resistance of the wires. The normal load during contact resistance measurements was varied from 1 to $5 \mathrm{~N}$. All measurements were carried out against a commercial Au-coated probe K60.05.33 (from Fixtest, Germany) with a hemispherical tip with $\Phi 3.3 \mathrm{~mm}$.

\section{Results}

The lubricating effect of graphene was evaluated by measurements of friction coefficients of a clean Ag surface and a graphene-modified Ag surface using three different counter materials $\mathrm{Ag}$, steel, and W. In the following the graphene-free systems are denoted $\mathrm{Ag} / \mathrm{Ag}$, steel/Ag, and W/Ag while the graphene-modified systems are denoted Ag/GL/Ag, steel/GL/Ag, and W/GL/Ag, respectively. During the initial experiments, we observed a variation in results also for the same set of counter materials. A general observation was that the graphene solution was susceptible to aging and that the lubricating effect of the applied gra- 
phene solution decreased by time. Furthermore, some variation in e.g., friction coefficient was also observed between different experiments. Thus the results presented below shows a representative set of observations where the general trends between materials will be demonstrated.

A typical set of friction curves for the different materials pairs with and without added graphene are shown in Fig. 1. The optical micrographs and profiles of the tracks for each tribotest are also included as insets. As can be seen, a dramatic reduction of the friction coefficient is observed after addition of graphene, in particular for the $\mathrm{Ag} / \mathrm{GL} / \mathrm{Ag}$ system. In addition, the roughness of tracks is also affected by the addition of graphene.

As shown in Fig. 1a, $\mathrm{Ag} / \mathrm{Ag}$ performed poorly with a high and fluctuating friction coefficient $(\sim 1.15)$. The optical micrograph shows that the $\mathrm{Ag} / \mathrm{Ag}$ pair suffered severe adhesive material transfer between the surfaces, which is also illustrated by the profile of the track surface. With addition of graphene, however, the friction coefficient was reduced remarkably to around $0.2-0.25$ initially. Typically, the friction was reduced with time and reached a value of $0.1-0.15$ after 1000 laps. However, a friction coefficient as low as 0.05 was observed in some experiments. In the $\mathrm{Ag} / \mathrm{Ag}$ pair, the high tendency for adhesion gives a strong interface, similar in strength to the two mating materials, and promotes material transfer and a large area of contact. All of these effects result in a high roughness of the contact track and a high friction coefficient for the $\mathrm{Ag} / \mathrm{Ag}$ pair. However, GL weaken the 'interface', where it is deposited, and thus provide a preferred shear plane, resulting in less adhesion, less material transfer, a smoother track, and a lower friction coefficient in the $\mathrm{Ag} / \mathrm{GL} / \mathrm{Ag}$ pair.

The steel/Ag pair initially shows a very low friction coefficient (0.15), due to the low roughness of steel ball, resulting in a delayed onset of adhesion. After 50 cycles, the friction coefficient gradually starts to increase to $\sim 0.85$. With addition of graphene, the friction coefficient was reduced from about 0.85 (steel/Ag) to 0.15 (steel/GL/ $\mathrm{Ag}$ ) after 1500 cycles. The example in Fig. 1b shows an experiment where the friction in the steel/GL/Ag pair initially was below 0.1 and increased to about 0.15 . The optical micrographs and height profiles of the tracks illustrates a rough track surface and ridges piling up to a similar volume as the groove in the steel/Ag track, indicating a combination of adhesive material transfer and plastic deformation of the Ag surface in the steel/Ag pair. With addition of graphene, however, almost no adhesive material transfer is visible in the steel/GL/Ag track, instead plastic deformation dominates completely.

As shown in Fig. 1c, graphene also improves the tribological behavior of the W/Ag pair. The addition of graphene decreased the friction coefficient from 0.75 (W/
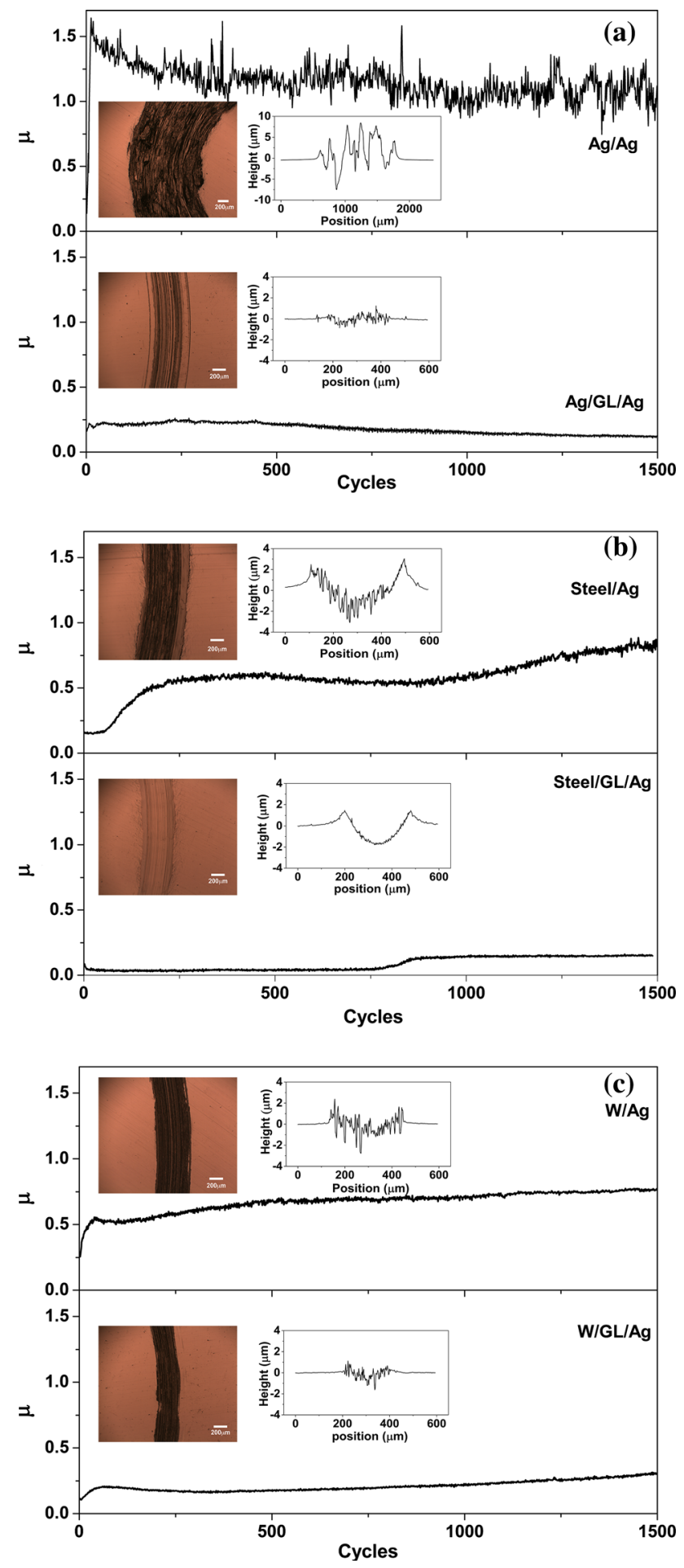

Fig. 1 Friction coefficients $(\mu$ ), optical micrographs (scale bar $200 \mu \mathrm{m})$ and height profiles of the tracks from the pin-on-disk tests (load: $1 \mathrm{~N}$ ) for $\mathbf{a} \mathrm{Ag}$, b steel, and $\mathbf{c} \mathrm{W}$ against $\mathrm{Ag}$ plate with and without graphene deposition. All tribological tests were manually stopped after 1500 cycles

$\mathrm{Ag})$ to $0.45(\mathrm{~W} / \mathrm{GL} / \mathrm{Ag})$. The height profile of W/Ag track shows a combination of adhesive transfer and plastic deformation, similar as steel/Ag track. However, with 
addition of graphene, unlike the steel/GL/Ag pair, some adhesive material transfer is evident in the W/GL/Ag track. The results in Fig. 1 show that graphene was a less effective lubricant with $\mathrm{W}$ as a counter surface than with $\mathrm{Ag}$ and steel as counter surfaces.

The results in Fig. 1, from tests carried out at a $1 \mathrm{~N}$ load, clearly show a lubricating effect with graphene strongly influenced by the metal in the counter surface. To further study this effect, a lifetime study was performed. In a first experiment, a $\mathrm{Ag} / \mathrm{GL} / \mathrm{Ag}$ pair was tested at $1 \mathrm{~N}$ (black curve in Fig. 2). This system showed a friction coefficient about 0.06 . The test was terminated after about 150,000 laps without loss of lubricating effect. Berman et al. have observed that the lubricating effect of graphene is load dependent [15]. A second set of experiments were therefore carried out at $2 \mathrm{~N}$. In this case, the Ag/GL/Ag pair showed a slightly higher friction coefficient for more than 40,000 laps, followed by a rapid increase in friction probably due to a loss of lubrication. In contrast, both the steel/GL/Ag and W/GL/Ag pairs showed a considerably lower lifetime in our experimental set-up. The lifetime of the steel/GL/Ag pair was determined to about 2700 cycles (not even

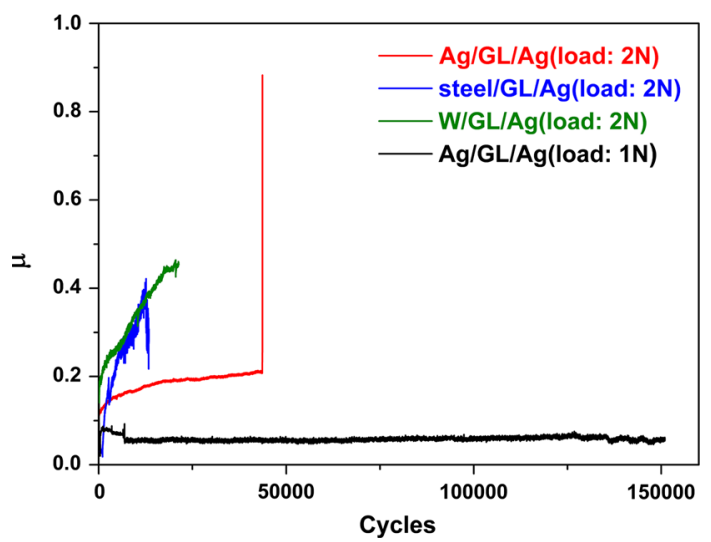

Fig. 2 Lifetime testings of lubricating graphene in the tribological pairs of different metal counter surfaces (Ag, Steel, and W) against the graphene-coated Ag plate discernible in Fig. 2) when the friction coefficient starts to fluctuate and increase gradually to high values. The corresponding life time for the W/GL/Ag pair was determined to be only about 500 cycles.

SEM and Raman spectroscopy were used to characterize the surfaces after addition of graphene on Ag. As shown in Fig. 3a, after evaporation of the ethanol, grayish flakes on the surface can be seen in the SEM images. It is clear that the size of the deposited flakes varies with massive amount of flakes less than $1 \mu \mathrm{m}$ in diameter. It also shows that the silver surface is not fully covered by the deposited flakes. Raman spectroscopy confirms that the flakes indeed are graphene (see Fig. 3b). The characteristic peaks of graphene were observed at $\sim 1330 \mathrm{~cm}^{-1}$ (D peak), $\sim 1600 \mathrm{~cm}^{-1}$ (G peak) and $\sim 2650 \mathrm{~cm}^{-1}$ (2D peak). The $\mathrm{D}$ peak is due to a breathing mode of $\mathrm{sp}^{2}$ atoms in rings, which is activated by disordered structures, e.g., edges or defects from partial oxidation of graphene [16-19]. The D peak is quite strong, indicating a large amount of disordered structures, e.g., edges or partial oxidation in graphene flakes. The Raman results suggest that the flakes consist of few-layer graphene, very similar to those observed by Berman et al. on steel surfaces [15].

To further study the lubricating effect of the GL, Raman spectroscopy was also carried out inside the track after the completion of the dry sliding tribological tests. The Raman spectra and the SEM images of the tracks are shown in Fig. 4. The track of the $\mathrm{Ag} / \mathrm{Ag}$ pair clearly suggests an adhesive material transfer as observed in Fig. 1. In contrast, the SEM image of the Ag/GL/Ag pair shows a microscopic plowing pattern with plenty of grayish flakes remaining in the track. The existence of GL in the tracks after 1500 cycles was also confirmed by the characteristic Raman spectrum, which is almost identical to that from asdeposited flakes in Fig. 3. The SEM images from the steel/ $\mathrm{Ag}$ and steel/GL/Ag pairs also confirm that graphene has a strong impact of the tribological behavior. The track in the steel/Ag pair shows adhesive material transfer mixed with plowing while the steel/GL/Ag pair only exhibits minute
Fig. 3 a SEM image and b Raman spectrum of asdeposited graphene flakes on $\mathrm{Ag}$ plate surface before pin-on-disk test. Scale bar for SEM image is $2 \mu \mathrm{m}$
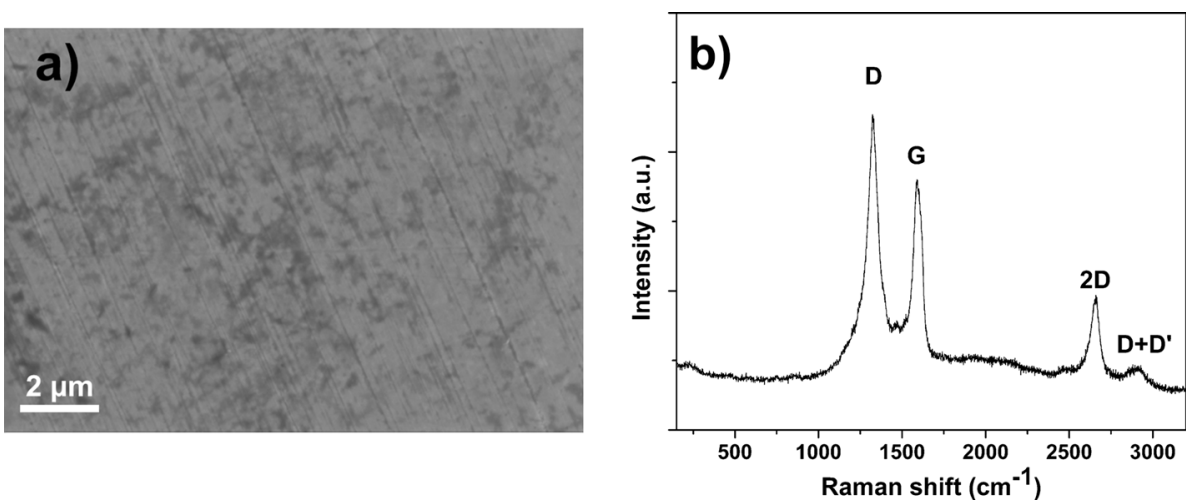

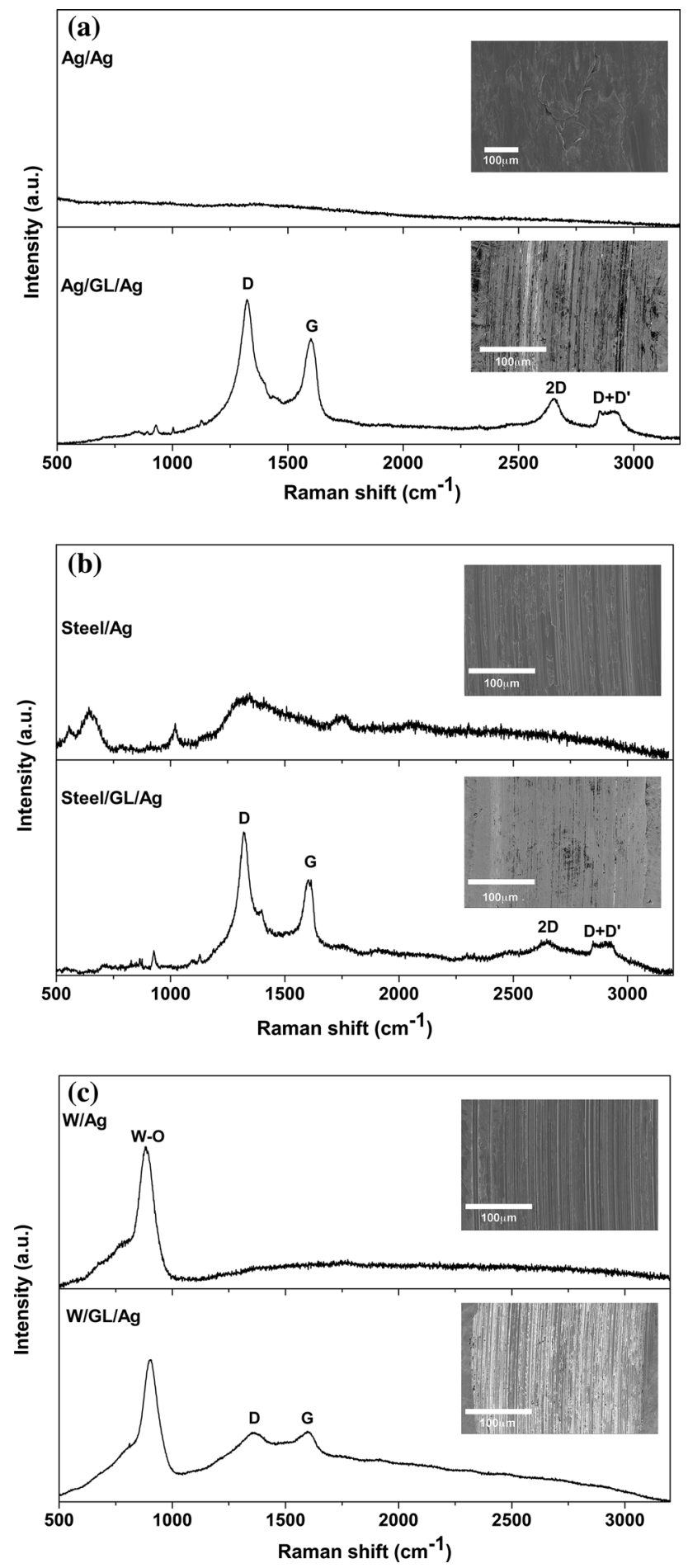

Fig. 4 Raman spectra and SEM images for the tracks on the Ag plate with and without graphene deposition after pin-on-disk tests using different counters: a Ag ball; b steel ball; and $\mathbf{c} \mathrm{W}$ ball. Scale bar for SEM images are $100 \mu \mathrm{m}$

plowing with remains of grayish flakes. The Raman spectrum from the steel/Ag track shows a number of peaks e.g., at $\sim 560,650$, and $1320 \mathrm{~cm}^{-1}$. These peaks can be attributed to metal oxides such as $\mathrm{Fe}_{2} \mathrm{O}_{3}$ which has been

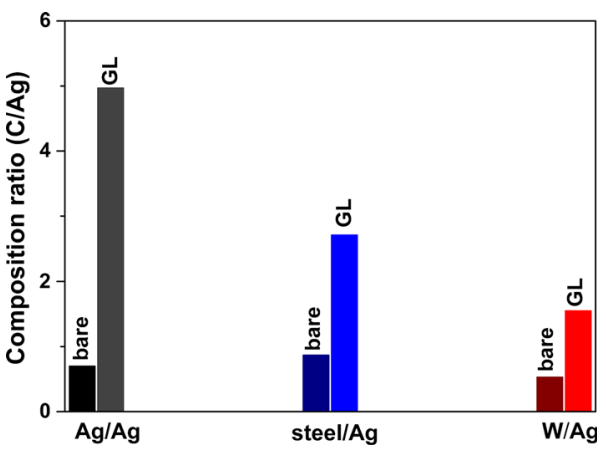

Fig. 5 Composition ratio of $\mathrm{C} / \mathrm{Ag}$ inside the tracks on the $\mathrm{Ag}$ plate after pin-on-disk tests using different counter surfaces

transferred from the steel ball to the Ag surface during the tribological test [20]. In contrast, the Raman spectrum from the steel/GL/Ag track shows clear peaks from graphene, similar to the Ag/GL/Ag case, but no metal oxide peaks. This shows that the presence of graphene has a strong influence on the tribological behavior also with steel as a counter surface. A completely different behavior was observed with $\mathrm{W}$ as a counter material. The Raman spectrum from the W/Ag track shows a strong peak W-O at $\sim 900 \mathrm{~cm}^{-1}$ suggesting an extensive formation of tungsten oxides in the track [21]. Upon addition of graphene, the W/GL/Ag track shows very few graphene flakes in SEM. Furthermore, the $\mathrm{W}-\mathrm{O}$ peak is still clearly seen in the Raman spectrum but only very weak and broad D and G peaks are observed. Such peaks are typical for amorphous carbon and suggest that the graphene has been highly damaged or completely destroyed during the sliding test.

XPS analysis can give supplementary information about graphene coverage inside the tracks through the C/Ag composition ratio. As shown in Fig. 5, the composition ratio of C/Ag inside the tracks of the three bare metals/Ag was almost similar to 1 , which means that there were some carbon contaminations on the bare track surface after the tribological tests. This originates from the carbon-containing contaminants adsorbed on the surfaces. In contrast, the three metals/GL/Ag pairs, exhibit significantly higher C/Ag ratios in the tracks. The $\mathrm{Ag} / \mathrm{GL} / \mathrm{Ag}$ track exhibits a higher ratio than steel/GL/Ag and considerably larger than that for the W/GK/Ag track. This result is consistent with the Raman and SEM results that plenty of graphene remains in Ag/GL/ Ag track and less graphene left in the W/GL/Ag track.

To understand the reasons for different tribological behaviors in different metal-graphene interfaces, XPS was used to analyze the chemical bonding in the tracks of different metals/GL/Ag pairs. As shown in Fig. 6a, Ag, C, and $\mathrm{O}$ signals were detected in all tracks. The $\mathrm{C} 1 \mathrm{~s}$ peak could originate from a mixture of remaining graphene flakes and other carbon contaminations. The $\mathrm{O}$ can be attributed to partially oxidized graphene or oxidized metal particles 

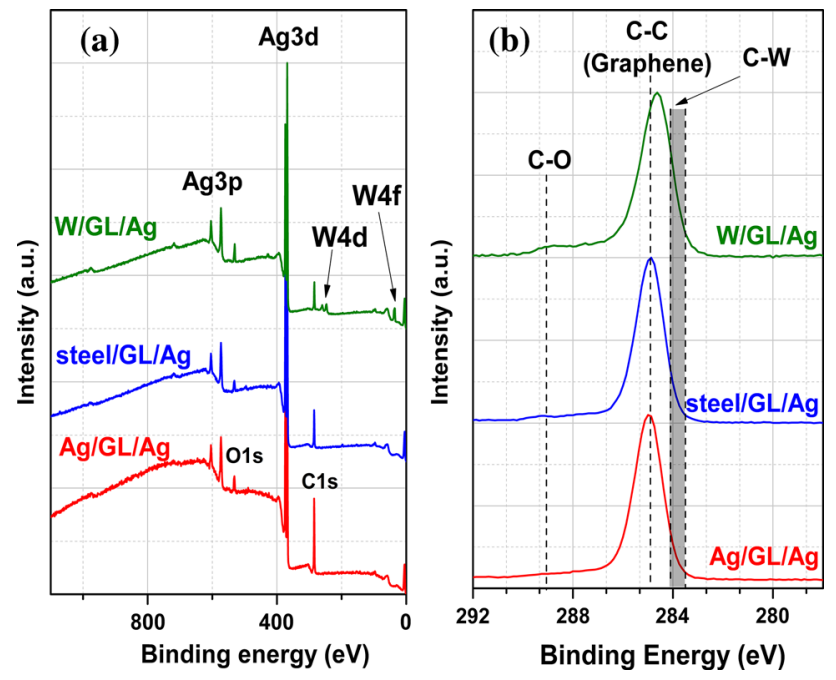

Fig. 6 a Survey XPS spectra and $\mathbf{b}$ high resolution XPS spectra of $\mathrm{C} 1$ s peaks for the track surface on the graphene-coated Ag plate after pin-on-disk tests using different metal counters

formed during the sliding tests. Some organic contaminants can also contribute. It is interesting to notice that $\mathrm{W}$ peaks were also observed in the XPS spectrum from the track of the W/GL/Ag pair, while no Fe peaks were seen in the spectrum from the steel/GL/Ag track. This indicates that $\mathrm{W}$ has been transferred to the $\mathrm{Ag}$ surface from the $\mathrm{W}$ ball during sliding while no such transfer occurs from the steel ball. High resolution spectra from the W4f peak indicate that the $\mathrm{W}$ is oxidized (not shown here).

High resolution spectra of the C1s peak obtained after 1500 cycles are shown in Fig. 6b. In the track of Ag/GL/ $\mathrm{Ag}$, a C1s peak is observed at $284.8 \mathrm{eV}$, which can be attributed to mainly $\mathrm{C}-\mathrm{C}$ bonds in graphene [22]. Also, the C1s peaks show weak contribution around $289 \mathrm{eV}$ which can be attributed to a type of $\mathrm{C}-\mathrm{O}$ bonds. The relative intensity of the $\mathrm{C}-\mathrm{O}$ contribution is slightly higher for the steel/GL/Ag par and significantly higher for the W/GL/Ag pair. This suggests a somewhat stronger oxidation of the GL with a steel counter surface. Furthermore, for the W/GL/Ag pair, the C1s peak is shifted with $0.2 \mathrm{eV}$ to a lower binding energy together with an increase in the intensity of $\mathrm{C}-\mathrm{O}$ feature. This shift suggests a strong interaction of carbon with a metal such as $\mathrm{W}$. The peak shift is not an indication of the formation of a hexagonal WC phase since the $\mathrm{C} 1 \mathrm{~s}$ peak in this compound is observed at $283.5 \mathrm{eV}$. However, the $\mathrm{C}-\mathrm{W}$ binding energy is strongly dependent on the type of $\mathrm{W}-\mathrm{C}$ coordination and, for example, a binding energy of $284.1 \mathrm{eV}$ has been observed in $\mathrm{W}_{2} \mathrm{C}$ [23]. It can be concluded, however, that the peak shift and increased $\mathrm{C}-\mathrm{O}$ intensity is in good agreement with a decomposition of the graphene flakes in the W/GL/ Ag track and the formation of amorphous carbon and some type of $\mathrm{W}-\mathrm{C}$ compound.

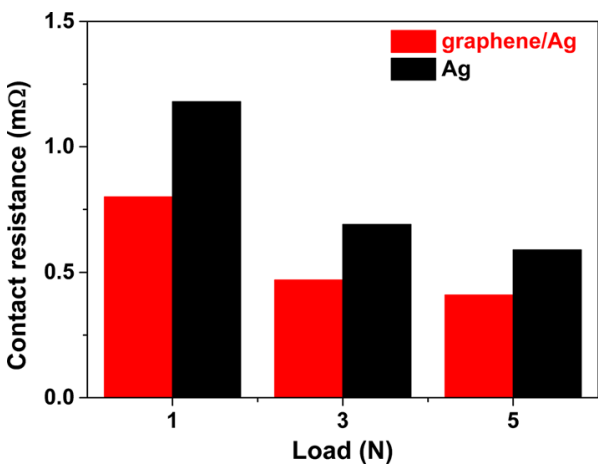

Fig. 7 Contact resistance of Ag and graphene-coated Ag (graphene/ $\mathrm{Ag}$ ) surface for different loads

The contact resistance of graphene-coated Ag surfaces was also evaluated using a four-point resistance method. A general observation was that the addition of graphene slightly reduced the contact resistance compared to the pure Ag surface, but at a similar level, as shown in Fig. 7. The graphene-coated $\mathrm{Ag}$ surface exhibited a contact resistance of $0.8 \mathrm{~m} \Omega$, compared to $1.18 \mathrm{~m} \Omega$ for pure $\mathrm{Ag}$ at a normal load of $1 \mathrm{~N}$. The deviations decrease with increasing load, e.g., $0.41 \mathrm{~m} \Omega$ for graphene/Ag and $0.59 \mathrm{~m} \Omega$ for Ag using $5 \mathrm{~N}$. Graphene as a zero-overlap semimetal (with both holes and electrons as charge carriers) with very high electrical conductivity could be the main contribution for the good contact property of graphene-coated Ag surface [24].

\section{Discussion}

Our results clearly show that graphene is an excellent lubricant in $\mathrm{Ag} / \mathrm{GL} / \mathrm{Ag}$ contacts. In contrast, graphene showed a lubricating effect with tungsten as a counter surface but the friction coefficient was higher and the lifetime of the graphene was much shorter. The steel/GL/ $\mathrm{Ag}$ pair showed an intermediate behavior. There are two main mechanisms which may contribute to these results: (i) the general trend in the $\mathrm{Me}-\mathrm{C}$ bond strength and the Me-graphene interactions and (ii) the mechanical deformation mechanisms in the metal/GL/Ag contacts.

Our XPS and Raman results clearly suggest that graphene on $\mathrm{W}$ in the track is highly damaged and probably partly decomposed. The shift of the XPS C1s peak suggests a strong $\mathrm{C}-\mathrm{W}$ interaction between the metal and damaged graphene and/or partial formation of a $\mathrm{C}-\mathrm{W}$ compound. No direct indications of such decomposition were observed on $\mathrm{Ag}$ or steel. It is clear that chemical interactions between metals and carbon are strongly dependent on the position of the metal in the periodic table. In general, the $\mathrm{Me}-\mathrm{C}$ bond strength decreases with increasing number of d-electrons in the metal. In our study, the $\mathrm{W}-\mathrm{C}$ bond strength is rather 
high and several tungsten carbide phases are known with the hexagonal WC phase an illustrative example. The $\mathrm{Fe}-\mathrm{C}$ bonds are weaker and only metastable iron carbides are known. Finally, the $\mathrm{Ag}-\mathrm{C}$ interactions are very weak and no stable or metastable silver carbides are known. Consequently, from a thermodynamic point of view, a driving force exists to form carbides by a chemical reaction between $\mathrm{W}$ and graphene while no such driving force exists for Fe and Ag. Secondly, the kinetics of decomposition of graphene can be strongly affected by $\mathrm{Me}-\mathrm{C}$ interactions. A change of charge transfer can dramatically change the stability of a molecule due to changes in the bonding/antibonding states. Theoretical calculations on adsorption of graphene have shown mainly weak adsorption (physisorption) on late transition metals such as $\mathrm{Cu}, \mathrm{Ag}$, and $\mathrm{Au}$ while a much stronger interactions including chemisorptions can be observed on Co and $\mathrm{Ni}$ [25-27]. Hence, from a pure chemical point of we should expect strong interactions between graphene and $\mathrm{W}$ and to some extent also Fe. This can explain the general trends observed in the tribological properties described above.

An alternative explanation to the observed trends in friction could possibly be variations in the mechanical deformation mechanisms in the metal/GL/Ag contacts. The tracks after tribological tests indeed look very different; some shallow and some extending to large depths. But when comparing the different tribological behaviors, it is important to keep the vast differences in mechanical strength in mind and to separate the mechanical plastic deformation from the more interesting tribological mechanisms behind the friction coefficients. Ag is a very soft metal known for very limited strain hardening. In any contact with considerably harder materials, like steel or $\mathrm{W}$, only the Ag will deform plastically. This means that the steel balls, the $\mathrm{W}$ balls and even the Ag tips used in this work will all be pressed into the silver counter material until the contact area has grown sufficiently large to make the contact pressure match the hardness of $\mathrm{Ag}$. In other words, the contact pressure will be very similar for all three (or six) pairs tested here, despite the fact that the radii of the spherical bodies differ somewhat. And despite the fact that the specific shapes of the tracks will be different. This holds both initially, at first contact, and during the subsequent mechanical deformation occurring during the tribological testing. In other words, the much harder steel and W will merely serve to shape the surface of the track in Ag, on which the crucial tribological mechanisms will take place, i.e., material transfer, graphene retention or decomposition, oxidation, etc.

However, once material transfer commence, the shape of the components will degrade. This is very clearly demonstrated by the $\mathrm{Ag} / \mathrm{Ag}$ pair where the initially spherical against flat geometry is completely lost due to excessive material transfer. A strong intermetallic bond, as in the $\mathrm{Ag} / \mathrm{Ag}$ pair, is of course very effective in initiating material transfer. All other pairs tested, and especially those with interfaces containing graphene, will be less prone to material transfer. But once it is initiated, the surfaces will begin to degrade and the effectiveness of any graphene present in the surface will be reduced further.

Consequently, we conclude that the most likely explanation for the observed trend in tribological behavior is variations in the chemical interactions between metal and graphene.

\section{Conclusion}

In this study, the potential use of GL as a solid lubricant on sliding Ag electrical contact was investigated. It has been shown that small amount of graphene flakes, which can easily and quickly be deposited by evaporating a commercial solution in air, can dramatically reduce friction in dry sliding $\mathrm{Ag} / \mathrm{Ag}$ contacts. With the lubricating effect of the graphene flakes, the friction coefficient was reduced by a factor of $\sim 10$ (e.g., from 1.15 to 0.12 ). Moreover, the track was much smoother, showing almost no signs of adhesive material transfer. The lifetime of the lubricating graphene was very long and the contact resistance for graphene/Ag surface was similar to pure Ag.

The lubricating effect was dependent on the counter surface. The Ag/GL/Ag contact exhibited the lowest friction coefficient and longest lifetime $(>40,000$ cylces at $2 \mathrm{~N}$ ). In contrast, the steel/GL/Ag and W/GL/Ag exhibited higher friction coefficients and shorter lifetimes. The lifetime of the W/GL/Ag pair was only 500 cycles. Metalgraphene interaction is believed to be the main reason for the differences in friction reduction, where $\mathrm{W}$-graphene shows the strongest bonds and $\mathrm{Ag}$ the weakest. Fe-based alloys such as steel exhibits intermediate bond strength to graphene. Therefore, the friction reduction with graphene lubrication increased in the sequence $\mathrm{Ag}$ ball $>$ steel ball $>\mathrm{W}$ ball. Alternative models to explain the trend, such as variations in hardness between the counter surfaces could be excluded due to the softness of the Ag surface. Overall, the deposited GL holds a great promise as an effective solid lubricant to significantly reduce friction in sliding Ag electrical contacts, especially in such a simple, quick, energy-saving, and cost-efficient way.

Acknowledgements The authors wish to acknowledge the financial support of the KIC InnoEnergy and the Swedish Centre for Smart Grids and Energy Storage (SweGRIDS). We also want to thank Pedro Berastegui for his technical support. Ulf Jansson also acknowledges Knut och Alice Wallenberg (KaW) foundation for support. Urban Wiklund also acknowledges the Swedish Foundation for Strategic Research (via the program Technical advancement through controlled tribofilms) for the financial support. 
Open Access This article is distributed under the terms of the Creative Commons Attribution 4.0 International License (http://creativecommons.org/licenses/by/4.0/), which permits unrestricted use, distribution, and reproduction in any medium, provided you give appropriate credit to the original author(s) and the source, provide a link to the Creative Commons license, and indicate if changes were made.

\section{References}

1. Arnell S, Andersson G (2001) Silver iodide as a solid lubricant for power contacts. In: Proceedings of the forty-seventh IEEE holm conference on electrical contacts, 239-244. doi:10.1109/ holm.2001.953217

2. Lauridsen J, Eklund P, Lu J, Knutsson A, Odén M, Mannerbro R, Andersson AM, Hultman L (2012) Microstructural and chemical analysis of AgI coatings used as a solid lubricant in electrical sliding contacts. Tribol Lett 46(2):187-193. doi:10.1007/s11249012-9938-3

3. Sundberg J, Mao F, Andersson A, Wiklund U, Jansson U (2013) Solution-based synthesis of AgI coatings for low-friction applications. J Mater Sci 48(5):2236-2244. doi:10.1007/s10853-0126999-5

4. Gao Y, Hao P (2009) Mechanical properties of monolayer graphene under tensile and compressive loading. Physica E 41(8):1561-1566. doi:10.1016/j.physe.2009.04.033

5. Geim AK (2009) Graphene: status and prospects. Science 324(5934):1530-1534. doi:10.1126/science.1158877

6. Lee C, Wei X, Kysar JW, Hone J (2008) Measurement of the elastic properties and intrinsic strength of monolayer graphene. Science 321(5887):385-388. doi:10.2307/20054532

7. Stankovich S, Dikin DA, Dommett GHB, Kohlhaas KM, Zimney EJ, Stach EA, Piner RD, Nguyen ST, Ruoff RS (2006) Graphenebased composite materials. Nature 442(7100):282-286. doi:10. 1038/nature04969

8. Choudhary S, Mungse HP, Khatri OP (2012) Dispersion of alkylated graphene in organic solvents and its potential for lubrication applications. J Mater Chem 22(39):21032-21039. doi:10.1039/c2jm34741e

9. Kandanur SS, Rafiee MA, Yavari F, Schrameyer M, Yu Z-Z, Blanchet TA, Koratkar N (2012) Suppression of wear in graphene polymer composites. Carbon 50(9):3178-3183. doi:10.1016/j. carbon.2011.10.038

10. Lee C, Wei X, Li Q, Carpick R, Kysar JW, Hone J (2009) Elastic and frictional properties of graphene. Phys Status Solidi B 246(11-12):2562-2567. doi:10.1002/pssb.200982329

11. Lin J, Wang L, Chen G (2011) Modification of graphene platelets and their tribological properties as a lubricant additive. Tribol Lett 41(1):209-215. doi:10.1007/s11249-010-9702-5

12. Sandoz-Rosado EJ, Tertuliano OA, Terrell EJ (2012) An atomistic study of the abrasive wear and failure of graphene sheets when used as a solid lubricant and a comparison to diamond-like- carbon coatings. Carbon 50(11):4078-4084. doi:10.1016/j.car bon.2012.04.055

13. Berman D, Erdemir A, Sumant AV (2014) Graphene as a protective coating and superior lubricant for electrical contacts. Appl Phys Lett 105(23):231907. doi:10.1063/1.4903933

14. Berman D, Erdemir A, Sumant AV (2013) Few layer graphene to reduce wear and friction on sliding steel surfaces. Carbon 54:454-459. doi:10.1016/j.carbon.2012.11.061

15. Berman D, Erdemir A, Sumant AV (2013) Reduced wear and friction enabled by graphene layers on sliding steel surfaces in dry nitrogen. Carbon 59:167-175. doi:10.1016/j.carbon.2013.03. 006

16. Ferrari AC, Robertson J (2000) Interpretation of Raman spectra of disordered and amorphous carbon. Phys Rev B 61(20): 14095-14107

17. Pócsik I, Hundhausen M, Koós M, Ley L (1998) Origin of the D peak in the Raman spectrum of microcrystalline graphite. J NonCryst Solids 227-230, Part 2 (0):1083-1086. doi:10.1016/S00223093(98)00349-4

18. Ferrari AC (2007) Raman spectroscopy of graphene and graphite: disorder, electron-phonon coupling, doping and nonadiabatic effects. Solid State Commun 143(1-2):47-57. doi:10.1016/j.ssc. 2007.03.052

19. Ferrari AC, Meyer JC, Scardaci V, Casiraghi C, Lazzeri M, Mauri F, Piscanec S, Jiang D, Novoselov KS, Roth S, Geim AK (2006) Raman spectrum of graphene and graphene layers. Phys Rev Lett. doi:10.1103/PhysRevLett.97.187401

20. Muralha VSF, Rehren T, Clark RJH (2011) Characterization of an iron smelting slag from Zimbabwe by Raman microscopy and electron beam analysis. J Raman Spectrosc 42(12):2077-2084. doi:10.1002/jrs.2961

21. Voevodin AA, O’Neill JP, Zabinski JS (1999) Tribological performance and tribochemistry of nanocrystalline WC/amorphous diamond-like carbon composites. Thin Solid Films 342(1-2): 194-200. doi:10.1016/S0040-6090(98)01456-4

22. Ferrah D, Penuelas J, Bottela C, Grenet G, Ouerghi A (2013) X-ray photoelectron spectroscopy (XPS) and diffraction (XPD) study of a few layers of graphene on $6 \mathrm{H}-\mathrm{SiC}(0001)$. Surf Sci 615:47-56. doi:10.1016/j.susc.2013.04.006

23. Aizawa T, Hishita S, Tanaka T, Otani S (2011) Surface reconstruction of W2C(0001). J Phys-Condens Mat 23(30):305007

24. Castro Neto AH, Guinea F, Peres NMR, Novoselov KS, Geim AK (2009) The electronic properties of graphene. Rev Mod Phys 81(1):109-162

25. Xu Z, Buehler MJ (2010) Interface structure and mechanics between graphene and metal substrates: a first-principles study. J Phys 22(48):485301

26. Giovannetti G, Khomyakov PA, Brocks G, Karpan VM, van den Brink J, Kelly PJ (2008) Doping graphene with metal contacts. Phys Rev Lett 101(2):026803

27. Andersen M, Hornekær L, Hammer B (2012) Graphene on metal surfaces and its hydrogen adsorption: a meta-GGA functional study. Phys Rev B 86(8):085405 